\title{
EL PAPILOMAVIRUS HUMANO EN LA DETECCIÓN DEL CÁNCER DE CÉRVIX
}

Margarita Ruiz Rubiano, $M D^{*}$

El descubrimiento del papilomavirus humano (PVH) como factor etiológico de la mayoría de las neoplasias de cuello uterino y en general de todo el tracto genital inferior, se ha considerado uno de los avances más importantes en la medicina actual. El PVH se encuentra relacionado con el cáncer cervical en el $99.7 \%$ de los casos y con el de vulva y vagina en $70-80 \%{ }^{1}$

Desde 1980 cuando Harold Zur Hausen, virólogo alemán, demostró por primera vez la relación entre el tumor cervical y el PVH, se han realizado múltiples estudios de prevalencia, de casos y controles y de cohorte, ${ }^{2-6}$ que constituyen la evidencia del riesgo carcinogénico del PVH y en particular de los tipos 16 y 18 . Se ha identificado el ADN viral en más de 200 tipos de PVH y han sido clasificados según su asociación con el cáncer de cérvix en virus de alto y bajo riesgo. Desde 1995 la Agencia Internacional de Investigaciones sobre el Cáncer (IARC) catalogó a los PVH tipos 16 y 18 como carcinógenos para los humanos (categoría de carcinogénesis grupo 1) y los tipos 31 y 33 como probablemente carcinógenos para los humanos (grupo $2 \mathrm{~A}$ ). ${ }^{7}$

Se estima que la incidencia de carcinoma de cérvix a nivel mundial es de 500.000 nuevos casos por año, siendo el segundo tumor maligno más común en la mujer en los países desarrollados, luego del de mama, y el más frecuente en los países en desarrollo. ${ }^{8}$

El cáncer cervicouterino sigue considerándose un problema de salud pública y la ciencia médica ha dedicado gran parte de su potencial hacia su prevención.

Patóloga Hospital de San José. Decana Facultad de Citohistotecnología y Profesora Asociada Fundación Universitaria de Ciencias de la Salud.
El uso sistemático de la citología cervicovaginal y la colposcopia como métodos de tamización ha disminuido la incidencia de la neoplasia, sobre todo en los países desarrollados. En aquellos en desarrollo la baja cobertura, la calidad de la toma y lectura de citologías y la poca adherencia de las pacientes han afectado los programas de detección temprana. ${ }^{9} \mathrm{~A}$ pesar de ser acciones prioritarias para la salud pública, estas campañas no han tenido el impacto esperado en nuestro medio y es por esto que debemos cuestionar su orientación, ya que las medidas que se toman en la actualidad no están diseñadas para combatir el agente etiológico, a pesar de que éste se encuentra identificado. ¿No sería mejor estrategia encaminar todos los recursos a la erradicación del factor etiológico y no a la detección temprana de la enfermedad?

Para considerar la erradicación de la infección por PVH tenemos que hacer una revisión del estado óptimo de la inmunología en esta área, ya que el uso sistemático de vacunas ofrecería una solución no sólo profiláctica sino curativa para la neoplasia. Existen múltiples grupos de inmunólogos trabajando en este tema y hay varios tipos de vacunas en desarrollo, como las de vector vivo de tipo recombinante, las proteicas, aquellas con plásmidos de ADN y las de partículas virales recombinantes. Los trabajos de investigación sobre estas últimas son los más desarrollados en la actualidad. Son vacunas constituidas por partículas similares al virus (PSV), que contienen antígenos capsulares pero no $\mathrm{ADN}$ viral. Los antígenos capsulares del PVH tienen alta especificidad y no se produce protección cruzada entre los diferentes subtipos de PVH. La protección contra cada subtipo de PVH requiere por lo tanto de una vacuna constituida por las PSV de cada subtipo de virus. La vacuna ideal debe contener PSV de los virus de alto riesgo más frecuentes en la población. La gran variabilidad de la secuencia genó- 
mica del virus sumada a la alta especificidad antigénica de cada uno de los tipos y subtipos de PVH, han sido los principales inconvenientes para la creación de una vacuna eficaz. Las que se han propuesto se encuentran aún en fase de experimentación y nos brindan solo una expectativa a mediano plazo para encontrar un arma contra la infección por PVH. Por el momento debemos seguir orientando la prevención de la infección a la reducción de los factores de riesgo.

Por otro lado, el desarrollo de la biología celular $\mathrm{y}$ molecular ha puesto a nuestro servicio una amplia gama de métodos para detectar la presencia del PVH en las células cervicales. La hibridización in situ, las reacciones de peroxidasa-antiperoxidasa, la reacción en cadena de polimerasa y la captura de híbridos detectan el ADN viral con una alta especificidad y sensibilidad. Se han propuesto algunas modificaciones en las estrategias tradicionales de tamización del cáncer de cérvix que incluyen estos nuevos métodos de diagnóstico. Sin embargo, estudios muy extensos realizados mundialmente (ALTS $)^{10}$ sugieren que las pruebas de detección del ADN del PVH requieren recursos tecnológicos especializados y costosos que impiden el empleo masivo, y no pueden ser utilizados como método de tamización en la población general. Tienen su principal valor en las pacientes cuya citología vaginal detecta células escamosas atípicas de origen indeterminado (en inglés, ASCUS) del sistema de Bethesda, ya que identifica los PVH de alto y bajo riesgo. Las pacientes con ASCUS y PVH de alto riesgo determinado mediante detección de $\mathrm{ADN}$ viral serían remitidas a colposcopia, mientras que a aquellas con ASCUS y PVH de bajo riesgo se les recomendaría seguimiento con citología en seis meses. Esta medida disminuye hasta en un $44 \%$ la remisión a colpscopia y ha demostrado una buena relación costo-efectividad. ${ }^{11}$

En conclusión, la detección del ADN viral se debe emplear para diferenciar PVH de alto y bajo riesgo $y$ es de gran utilidad en el seguimiento de algunas pacientes cuando se usa en conjunto con la citología tradicional.

Recientemente en el país se han propuesto métodos serológicos que pretenden detectar anticuerpos espe- cíficos contra virus de alto riesgo $;{ }^{12}$ estas pruebas constituyen un índice de la infección por el PVH y no tienen valor diagnóstico. Además, se encuentran aún en fase de experimentación y se debe demostrar su validez antes de ser ofrecidas a la comunidad y promocionadas por los medios de comunicación. La Academia Nacional de Medicina de Colombia se ha pronunciado a este respecto y estimula a los investigadores a continuar sus estudios, pero ratifica que la citología vaginal o prueba de Papanicolaou continuará siendo la única e indiscutible prueba de detección temprana de cáncer de cérvix en nuestro país. $^{13}$

La citología convencional sigue por lo tanto siendo el método de elección de tamización para el cáncer de cérvix, tiene algunas limitaciones bien estudiadas y se han creado normas internacionales encaminadas a disminuir posibles errores, entre los cuales quiero resaltar: cada citotecnólogo debe leer máximo 80 láminas al día, se debe realizar sistemáticamente relectura del 10\% de láminas negativas y llevar un control de calidad riguroso, tanto interno como externo, en los laboratorios de citología.

El sistema Bethesda se revalúa permanentemente y en la actualidad refleja una profunda comprensión del desarrollo de la neoplasia cervical y permite un mejor entendimiento de los resultados. Han surgido nuevos métodos de procesamiento y toma de muestra para reducir los falsos negativos, como la citología en capa fina que ha demostrado un aumento con valor estadístico de la sensibilidad, por la obtención de muestras de mayor celularidad con menos artificios de fijación.

Todos estos avances nos permiten vislumbrar que poco a poco nos estamos acercando al final de una de las enfermedades que más afecta la población femenina. Por el momento es indispensable desarrollar protocolos que garanticen en forma estricta la calidad de los procesos tradicionales de tamización, que constituyen el programa actual de control de cáncer de cérvix, sin apartarnos de los beneficios que nos pueda traer la nueva tecnología, midiendo siempre su costo-efectividad en nuestro medio. 
El mundo cambia a diario y el progreso se impone en la lucha contra las enfermedades. La adaptación a nuevos procesos debe hacerse en condiciones de certeza acorde con recursos y prioridades.

La precaución y la investigación ceñida al rigor científico son valiosas herramientas en el arduo trabajo que en nuestro país desarrollan instituciones hospitalarias y universidades en la búsqueda del mejoramiento de las condiciones de salud de la población

\section{Referencias}

1. Campiomn M. Preinvasive Disease In: Berek J, Hacker N. Practical Gynecologic Oncology. Philadelphia: Lippincott, 2000.

2. Adam E, Berkova Z, Daxnerova J, Icenogle J, Reeves WC, Kaufman RH. Papillomavirus detection: Demographic and behavioral characteristics influencing the identification of cervical disease. Am J Obstet Gynecol 2000; 182(2): 257-64.

3. Cates W, and the American Social Health Association Panel. Estimates of the incidence and prevalence of sexually transmited diseases in the United States. Sex Transm Dis 1999; 26:S2-S7.

4. Boch FX, Muñoz N, Sanjosé de S, Navarro C, Moreo R. Et al. Human Papillomavirus and cervical intraepithelial neoplasia grade III/carcinoma in situ: a case control study in spain and Colombia. Cancer Epidemiol Biomarkers Prev 1993; 2:415-22.

5. Koutsky L.A, Holmes KK, Critchlow CW, Stevens C.E, Paavonen J, et al. A ohort study of the risk of cervical intrae- phitelial neoplasia grade 2 or 3 in relation the papillomavirus infection. N Engl J Med 1992; 327:1272-78.

6. Cubie HA, Seager AL, Beattie GJ, Monaghan S, Williams ARW. A longitudinal study if HPV detection and cervical pathology in HIV infected women. Sex Transm Infect 2000; 756:257-61.

7. International Agency for Research on Cancer. Evaluation of carcinogenic riks to humans. 1995. (IARC Monographs v.64 Human Papillomaviruses).

8. Schouten LJ, Hoppener P, Brandt van Den P, Knottnerus JA, et al. Cancer Incidence in Five Continentes. Lyon: IARC, 1992. (IARC Scientific Publication no. 120 v. 6).

9. Detección Oportuna del Cáncer del Cuello del Utero en América Latina y el Caribe. Informe Grupo de Trabajo Organización Panamericana de la Salud Nicaragua: OPS 1996.

10. Kim JJ, Wright TC, Goldie SJ. Cost- effectivenses of alteranative triage strategies for atypical squamous cells of undetermined significance. JAMA 2002; 287: 2382-90.

11. Koopmanschap MA, Oortmarssen van GA, Agt van HMA, Ballegooijen van M, Habbema JD, Lubbe KT Cervical cancer screening: attendance and cost-effectivensess. Int J. Cancer 1990: 45:410-15.

12. Urquiza M, Guevara T, Espejo F, Bravo MB, Rivera Z, Patarroyo ME. Two L1-peptides are excellent tools for serological detection of HPV-associated cervical carcinoma lesions. BBRC 2005; 332:224-32.

13. Academia Nacional de Medicina, Bogotá. Comunicado a la opinión pública sobre el trabajo de investigación de la Fundación Instituto de Inmunología de Colombia, bajo la dirección del académico honorario doctor Manuel Elkin Patarroyo. Bogotá: 2005. 2h. 